INTERNATIONAL JOURNAL OF

ARTIFICIAL INTELLIGENCE AND EMERGING

TECHNOLOGY

VOLUME 2, ISSUE 1, 2019, 9-24.

www.egyptfuture.org/ojs/

\title{
MODERN TECHNOLOGY AND ITS IMPACT ON THE CONCEPT OF CONTEMPORARY INTERIOR DESIGN
}

\author{
Salma Youssef Wahba Ali Karrar* \\ Faculty of Arts and Design - Interior Architecture - Pharos University
}

, Alexandria, Egypt

\begin{abstract}
Science is developing significantly in all fields, and of course this development serves the person, and the designer is always looking for everything new and modern that makes his design more successful. The more the designer introduces modern techniques to the design of the internal space, the more contemporary the space becomes, and saves a lot of time and effort, whether for him or for the occupant of the vacuum. Modern technology has provided many and many design solutions and produced spaces that are functionally and aesthetically successful.

The world is now heading to the use of modern technologies and advanced technology that achieve savings, whether by energy or raw materials, which also serve the human need and fit with the internal void and its modern requirements and functions, keeping pace with progress and modernity, linking the present with the future, and integrating the originality of thought and environmental character with technology and development.

The internal space becomes a smart space in which multiple systems of energy use, temperature control, lighting, sound and communications are compatible, as electronic systems are introduced that work to control different systems of lighting, air conditioning, energy, etc., hence the importance of the research as the research presents applications for the use of technology And modern technologies in interior architecture, and their impact on the concept and vocabulary of interior design Keywords

New technology- Interior Design-Smart Void
\end{abstract}

\section{Introduction:}

Technological development must be based on community service and not vice versa.

Development is not a beneficial development when it harms the environment or human beings. Technology and the great industrial development in the late sixties and early seventies had an adverse effect on the environment, where many environmental problems such as environmental pollution appeared, as well as the energy crisis. Globalization, which pushed the world at that time towards a stage of transformation, so it began to stop, review the negative effects resulting from this development, correct this path in all respects, and make peace with the environment, and that correction was reflected in architecture, so the

*Corresponding author: info@pua.edu.eg 
call for environmentally friendly buildings such as ecological, organic, green and sustainable architecture and others.

Environmental thought has evolved throughout history from ancient primitive architecture to smart architecture, where there are many forms of environmental architecture starting from the human interest in the surrounding environment where he is affected and interacted with it, so his interest in housing that protects him from it was the first factor that helped the emergence of environmental architecture, then the development of architecture Pre-modern era, right up to the first beginnings of contemporary architecture produced by the industrial era civilization, the historical architectural eras have been divided into: local architecture, heritage architecture, ecological architecture, climatic architecture, bioengineering architecture, organic architecture, solar architecture, green architecture, Technological architecture, smart architecture.

The research problem lies in how to reach technologically advanced standards that the interior designer can benefit from in designing his spaces with compatibility with the environment and not harming it, leading to a smart void that achieves the availability of functional, aesthetic and more technologically advanced aspects.

The research aims to find new design concepts that work to link between technology and its development, the surrounding environment, and the contemporary interior space that fulfills its functional and aesthetic requirements. 
The research is limited to studying the impact of technological development on interior design and how it affects positively on the environment and not negatively, achieving its goal of function and beauty.

\section{Methodology :}

The approach followed by the research, the descriptive analytical approach.

\section{Research fact_:}

Technological development saves time and effort and achieves faster results.

The environment is affected by any harmful factors that may result from the unexplained technological development.

The interior designer resorts to everything that is sophisticated and modern that meets his needs.

Technological development can be compatible with the environment without harming it.

\section{Theoretical Framework:}

:Environmental architecture and its evolution from local to smart architecture

Environmental engineering means taking care of everything related to the safety of the environment, and paying attention to the means of preserving this environment, which leads to the provision of a healthy, safe environment for the human being with the aim of preserving human safety, and environmental architecture emerged from ancient times and its product varied from one region to another and the goal of building in it was an attempt to adapt. With the surrounding environment merely for the human being to protect himself 
from it, and the environmental architecture had different forms that changed according to environmental factors, available resources and limited technologies at that time, and the huge technological and industrial development in the late sixties and early seventies had an adverse effect on the environment, and many environmental problems emerged, such as an increase in environmental pollution and the emergence of The global energy crisis, then a phase of transformation occurred, and a pause began, reconsidering the negative effects, correcting the path in all directions, and making a reconciliation with the environment. This awakening was reflected in architecture, so the call for eco-friendly, organic, green and sustainable buildings and others, and that new thought merged with the idea of smart architecture. Architecture that integrates scientific and technological development, taking into account the environment and not harming it.

\section{Architecture Intelligent :}

Technology is the different methods used in the practical application of science and knowledge, in other words, it is the human effort and the way of thinking in using the information, experiences and human skills available in a field and applying them to discover technological means for the comfort of a person and a dream he faces from problems to make life easier and more enjoyable.

Technology is not limited to one field of the environment, but it is used in various environmental fields. Its role is in education, scientific research, architecture, agriculture, 
industry and government interests. Hence, the prominent role of technology in the environment and its relationship to economic and social development appears.

Technology is an applied science that has its origins as it includes a set of inputs (individuals - theories - research - machines and equipment - ...) and outputs (the new method for solving the problem) and technology is not a goal but rather a means for the development of societies and through which we can reach many goals such as developing education. Scientific research, communications, medicine and engineering in all its fields and all other areas of life without exception.

Smart architecture showed interest in it at the beginning of the eighties of the twentieth century, and smart architecture is the smart building in its technological innovations and the collection of its services is managed by smart systems, and the "hi-tech" architecture was the first architectural trends that appeared in response to the call to use technology to achieve environmental goals, so it was an attempt to enable technology to meet And the environment, but it could not understand the future technology that later emerged from information technology and communication networks, and this is the difference between it and the smart architecture that appeared in the mid-eighties and used the latest current technological means, with its ability to absorb future technology, so it was the ideal practical model to provide the needs of the building occupants Under the information society, with its ability to adapt to the environment and adapt over the years according to the requirements and expected needs. 
Hence, smart architecture was the most effective architectural trend in creating a responsive and sustainable environment by achieving integration between technological systems and ecosystems, and therefore it is classified within the technological architectural trends and at the same time within the environmental architectural trends, because it was able practically and practically to solve the difficult equation in the use of advanced technology without creating The slightest damage to the ecosystem, and on the contrary, it helped to achieve the goals of environmental architecture and was the fruit of a reconciliation contract between technology and the environment.

\section{Technology goal in smart architecture:}

Accordingly, the goal of technology is to reach a more comfortable and luxurious world, which is a smarter and more flexible world of electronic property control, in a way that supports self-response and meets the desires of users without the need for direct human intervention. Hence the definition of smart architecture.

\section{Positive effects of technology on the environment:}

The widespread interest in the environment has prompted scientists and engineers to search for technical solutions to this issue. Some research attempts to find ways to eliminate or manage pollution, and others aim to prevent it. Many industrial researchers are working to find more economical ways to use fuel and other raw materials. As a result of this research, some European cities are currently using the waste heat from power plants and 
waste incinerators to heat homes. Modern engines burn fuel much cleaner and more

efficiently than older vehicles.

One of the best positive results of technology is access to ways to generate electricity at a lower cost than renewable resources such as wind and sun, which rarely result in any pollution. Wide fields of windmills, called wind farms, which contain many poles supply electricity, as photovoltaic cells convert sunlight directly into electricity.

Many companies have discovered that reducing pollution is required from a business perspective. Some have found that reducing pollution improves their public image and saves money. Others have developed products or methods that do not pose a threat to the environment, in order to gain the satisfaction of consumers. Others have also developed regulations to combat pollution because they believe that laws will compel them to do so, sooner or later. And some companies reduce pollution because the people in charge of these companies preferred to do so.

In the past, waste disposal was relatively inexpensive for most establishments. Today, the sites authorized for waste disposal are scarce, and the costs of using them have increased. Many institutions specialize in

Different types of pollution management methods and pollution reduction, or elimination, is expected to be one of the fastest growing industries of the future. For example, some pollution management institutions have developed devices to remove harmful fumes from chimneys. The fumes can be trapped using filters or traps that use static 
electricity. Some institutions and manages recycling and energy conservation programs. Some other institutions also help develop processes that reduce pollutants.

When the cost of eliminating pollution from current production methods is added to the manufacturing costs, it becomes clear that the less polluting methods are the best economically.

Technology has contributed to dropping barriers between people, whether their places and languages, and man deals with technology on an ongoing basis, as technology has become associated with humans in all his steps, which had a great impact in the field of architecture where technology worked on:

-Reducing the pressure on non-renewable nature energy resources

•Enhancing the use and increasing the efficiency of using the architectural system.

-Saving time and effort for building services.

\section{Smart architecture is a mature maturity of technology compatibility:}

Since prehistoric times, developments were the product of trial and error, and those who carried them out were not scientists and did not study theories, but rather that necessity was the mother of invention, so the close connection between the level of technology and the needs of society, as these developments depended on human instinct, technology is as old as the person who He provided for himself his material and spiritual needs without being a scientist in the modern sense of the word, as it was more environmentally friendly than some modern technologies that apply scientific knowledge whose age does not exceed a few 
hundred years, but after World War II, discontent with technology increased due to the effects that resulted from the war, and smart buildings The buildings in which the environmental systems are integrated from energy use, temperature control, lighting, and generalization in the term smart architecture to customization according to the function of the building, the classification of different types, sound, workplace and communications, the intelligent office building, the intelligent skyscraper of smart buildings, Intelligent houses, and even an Intelligent ci city, appeared.

\section{Technology and its impact on the environment:}

As much as technological progress helped explain environmental phenomena, as much as it contributed to their degradation over our planet, technological development affects humans positively and negatively at the same time, so the positive effect is to increase human knowledge and capabilities, while the negative effect is the presence of negative effects as a result of direct application without Sweeten it and try to understand its meanings.

With the beginning of the Industrial Revolution, or as it is called "the era of the subjugation of nature," several intellectual and engineering currents appeared that led to a comprehensive change in man's perspective on the world. In the past, the environment was stronger than man, with no one in front of it except to adapt and coexist with it. As for the emergence of scientific theories that explained natural phenomena. 
And she opened the door to control them, and with the revolution of gigantic machines, man no longer had to respect the environment and adapt to it, as he could simply change it, and thus began the era of heating, ventilation and air conditioning engineers, whose mission was to develop means to control the climatic conditions of buildings, starting from the end of the century. The eighteenth century, and their knowledge became well established in the first half of the nineteenth century, with dozens of technologies such as boilers, boilers, hot water or hot air distribution networks ... etc. The role of the architect is no longer to build a house that is compatible with natural climatic conditions, but rather he has to do whatever he wants. On the condition that adaptation engineers be provided with spaces to place their machines, and corridors to install central heating networks, and the complementary result of this revolution was that the architects removed from their minds environmental ideas, and left that to air conditioning engineers, and they devoted themselves to expressing the progress of the industrial age with the glass facades of buildings with light structural structures, and the publication began International style. This period was accompanied by the emergence of many architectural trends calling for the application of available technologies in this era, and perhaps the most important is the trend of "high-tech" that appeared in the West in the late sixties of the twentieth century, and calls for its owners to rely entirely on the application of the latest in industrial technology. Developed in building construction and express this explicitly, and the use of manufactured building materials 
instead of natural materials, and the preference for the processing and production of building

materials automatically in factories.

\section{Technology Smart Interior Design:}

The house has become not just a traditional living space for rest, relaxation and dining, but has become a place for work, communication and shopping as well, where means of Internet connection are available everywhere, and all amenities are available with the highest technology and technology has entered the internal space to provide all human needs and achieve all the required functions and achieve flexibility as well. Taking into account the selection criteria for furniture and products, while respecting the environment, whether it is the internal or external living environment, which questioned the designer to re-adapt the traditional concepts of interior design to suit the era of digital design, as form, space and function have acquired a new meaning now, for example the concept of job has changed As a result of technological development, where the primary goal of designing any interior space is to achieve interactive living with the necessity to make a change in the design and function of the design to suit the future needs of housing users.

Of course, architecture is closely related to interior design, the availability of technology and its application to the interior design, which transforms the building into a smart building as it integrates with all that surrounds it in terms of interaction that responds to environmental, humanitarian and design requirements through the use of modern technology and information technology, so smart design is interactive not only with the 
climate and the environment, but It also interacts with the social environment, and the historical environment, as it cooperates with and interacts with all of that.

Environmental systems are integrated in the design of energy use, temperature control, lighting, sound and communications. Electronic systems are used, especially in operating some parts of the building and controlling the various systems inside the building, such as lighting, air conditioning and energy systems.

The external facades have evolved from being a mere construction that protects the building from the climate to a more complex and interactive membrane, to act as an environmental surface concerned with achieving the transformation from the external climate to the internal climate through its integration with the building equipment. The roof has also become in the light of smart architecture plays a fundamental role in controlling the environment and the internal climate along with its interaction with the user and its appearance changes according to this interaction, for example a fast-response ceiling is a roof that contains a network system linked with each other as it works to provide the best conditions for ventilation, heat and lighting Natural.

As for the furniture, it has become multi-functional that does not occupy a large space while preserving the beautiful shape, in addition to the integration of the computer inside it to perform functions that were not familiar to it before, some furniture units have developed that are distinguished by the ability of the materials that make them to change their 
properties in terms of heating or mail according to the desire User to give him a feeling of thermal comfort.

As for the openings or windows, it can control its characteristics in terms of transparency and heat permeability, preventing sound disturbance, and smart shading of its parts can be by employing traditional components in a smart way, such as sun balls that change their angle of inclination to achieve the permeability of touch rays or prevent them from the building envelope as required.

\section{The basic factors of smart indoor vacuum:}

1- Internal network:The internal network The internal network is a unit consisting of several wires and wireless connections that work on connecting various devices such as lighting and irrigation systems, audio and video recording devices, heating, ventilation and other systems with the central control unit.

2- Internal control: The intelligent unit is the controlling and controlling mind in the secondary systems and devices inside a vacuum.

3- Computer screen: Computer screen: Through this screen, the user can follow the efficiency of the work of all devices used, as well as programming all his requirements.

There are three criteria that must be met to become a smart home:

1. The ability to know (input) 
2. The ability to respond (output).

3. Time factor and response time.

Knowledge covers all the received information and the data storage media through which the information is received and collected, which is known as (input) and the building responds at that time to temperature adjusting and with the building's response it becomes an adapting building and provides system outputs as it is called) Outputs (As for the time factor, it is an important and basic factor, as most of the outputs or inputs are required at a specific time and this is an invaluable factor that distinguishes smart buildings from other buildings. Hence, we find that the previous three factors (inputs, outputs and time factor) are the factors that make up any system Intelligent, but the development of means of remote communication led successively to the development of smart building systems, so another factor no less important than the previous ones appeared, which is "adaptability", so the smart building must be able to adapt to technology.

\section{Results :}

1- The designer must keep pace with technological development, as it saves time and effort and achieves faster results.

2- The designer must take advantage of the positive aspects of technological development, as the environment is affected by any harmful factors that may result from the unstudied technological development. 
3- The interior designer resorts to everything that is advanced and modern that meets his needs.

4- Technological development can be compatible with the environment without harming it.

\section{Recommendations:}

1- Every country differs from the other in its economic potential and thus its impact on the technological development of that

2- The designer must try to adapt to the development in a way that does not conflict with the available economic capabilities.

3- The continuity of all disciplines and academics and the joint cooperation with research is making great progress in different fields. Therefore, collective work must be resorted to and benefit from the different disciplines that ultimately serve the field of research.

\section{References}

1- Basem Salem Saleh Al-Khalqi Al-Yafei: “The Environment and its Impact on Design and Sustainable Development", 2018.

2- Olfat Abdulghani Suleiman: "Methodology of Architectural Design and Future Architecture”, 2018

3- Marwa Judeh Fadel Badran: "The shift between logic and creativity as an input to the intellectual process with the methodology of environmentally compatible architecture 2012" 
4- Doaa Ahmed Shehata Abu Al-Majd: "Total Energy and Architecture of the Poor", Delta University for

Science and Technology, Faculty of Engineering, Smart and Sustainable Architecture Research, 2015

5- Nagwa Ali Saeed Al-Hamshari, Mohamed Salah Rajaei: “The Environment and Technological Challenges”, Faculty of Engineering, Delta University of Science and Technology, 2015

6- Amjad Mahmoud Abdullah Al-Badri, Haider Asaad: "The concept of technical systems for the idea of smart building architecture” University - Baghdad College of Engineering, Department of Architecture, 2013

7- Khaled Ali Youssef: “Smart Architecture, Contemporary Formulation of Local Architecture,” PhD Thesis, Department of Architecture, Faculty of Engineering, Assiut University, 2017

8- Nasser Fawzi Ramadan: “An approach to measuring the environmental compatibility of building technology in housing projects", 2015

9- Rifaat Ali Ahmad Hamad: "The Impact of Technological Development and the Environment on the Architectural Void”, 2010

10- Omar bin Al-Hashemi bin Muhammad: “The Impact of Contemporary Technology on the Architectural Formation of Facades in the Arab World," 2010

11- Case study pearl river tower - How far can you go ?- by kyra Epstein-2018

12- http://architectureupdate.in/design-coalesce/

13-https://www.som.com/projects/pearl_river_tower_sustainable_design

14- https://archive.fortune.com/2010/02/22/technology/zeb_pearl_river.fortune/index.htm

15- https://writepass.com/journal/2012/11/feasibility-assessment-of-the-pearl-river-tower/

Received: December 25, 2018

Accepted: March 09, 2019 